Check for updates

Cite this: RSC Adv., 2017, 7, 39604

\title{
The synthesis of poly(phenylene sulfide sulfone) in ionic liquids at atmospheric pressure $\uparrow$
}

\author{
Dan He, Ying Wu, Zhengping Liu (D) and Tuo Zhao \\ A novel chemical approach to prepare the high performance polymer poly(phenylene sulfide sulfone) under \\ mild conditions was presented based on 4,4-difluorodiphenylsulfone and sodium sulfide $\left(\mathrm{Na}_{2} \mathrm{~S}\right)$ in i-pmim \\ $\mathrm{PF}_{6}$ (IL)/MImBS (ZI) at atmospheric pressure and compared with conventional methods. The highest \\ molecular weight $\left(2.5 \times 10^{4}\right)$ and yield $(>99 \%)$ polymers were synthesized in IL/ZI in the presence of \\ sodium carbonate and sodium hydroxide at $200{ }^{\circ} \mathrm{C}$ for $4 \mathrm{~h}$. Zl can significantly improve solubility of the \\ basic inorganic salt $\mathrm{Na}_{2} \mathrm{~S}$. And using ILs as solvents made removing toluene by purging with nitrogen \\ much easier and the time was shortened significantly from 5-8 min to 1-2 min. In addition, the ILs can \\ be recycled easily and still possess excellent performance.
}

Received 25th April 2017

Accepted 12th July 2017

DOI: 10.1039/c7ra04627h

rsc.li/rsc-advances

(halogen $=$ chlorine, preferably fluorine), solution polymeriza-

\section{Introduction}

Poly(arylene sulfide)s (PAS) are a kind of high performance polymers (HPP) containing sulfide with desirable properties such as excellent mechanical properties, high thermal stability, good resistance to chemical degradation and fire resistance under a wide range of conditions. As an important member of the PAS family, poly(phenylene sulfide sulfone) (PPSS) has received more and more attention in the past several decades (Fig. 1). PPSS is described as an amorphous polymer with a glass transition temperature $\left(T_{\mathrm{g}}=215^{\circ} \mathrm{C}\right)$ much higher than that of PPS $\left(T_{g}=93^{\circ} \mathrm{C}\right)$, as well as a similar degradation temperature $\left(T_{\mathrm{d}}=490^{\circ} \mathrm{C}\right)$.

As thermoplastic materials, PPSS is well known for several inherently attractive characteristics such as rapid processibility, etc. The applications of PPSS span across automotive, aerospace, weaponry, nuke industry and membrane technologies, etc. ${ }^{1,2}$

PPSS can be prepared by three main synthetic pathways: selfcondensation reaction of 4-(4-halophenylsulfonyl)benzenethiol

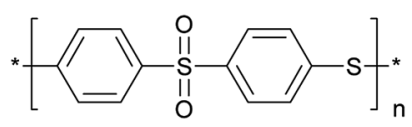

Fig. 1 Structure of PPSS.

Beijing Key Laboratory of Materials for Energy Conversion and Storage, BNU Key Lab of Environmentally Friendly and Functional Polymer Materials, College of Chemistry, Beijing Normal University, Beijing 100875, P. R. China. E-mail: lzp@bnu.edu.cn; Fax: +8610 58802075; Tel: +861058806896

$\dagger$ Electronic supplementary information (ESI) available. See DOI: $10.1039 / \mathrm{c} 7 \mathrm{ra} 04627 \mathrm{~h}$ tion of sulphur and 4,4'-dihalodiphenylsulfone, and solution polymerization of $\mathrm{Na}_{2} \mathrm{~S}$ (or sodium hydrosulfide) and 4,4'dihalodiphenyl-sulfone. Up to present, industrial PPSS was synthesized via nucleophilic aromatic substitution polycondensation $\left(\mathrm{S}_{\mathrm{N}} \mathrm{AR}\right)$ between $\mathrm{Na}_{2} \mathrm{~S}$ and 4,4'-dichlorophenylsulfone (DCDPS)/4,4'-difluorodiphenylsulfone (DFDPS). The reaction was performed in polar organic amine solvent at elevated reaction temperature $\left(\mathrm{ca} .180-230^{\circ} \mathrm{C}\right)$ and pressure in the presence of an alkali salt. Additionally, $\mathrm{Na}_{2} \mathrm{~S}$ and DCDPS/ DFDPS were utilized as the nucleophile and activated aromatic halide, respectively.

PPSS is generally synthesized in polar organic amine solvent and the most commonly used one is NMP. ${ }^{3-5}$ However, the high volatility of NMP limited its application of PPSS synthesis in high reaction temperature at atmospheric pressure, and the pressure reactor was needed, which made the synthetic process exhibit high energy consumption and demand special equipment. ${ }^{1}$ Therefore, novel solvent with high boiling point, high thermal stability and good solubility for the monomer and PPSS are strongly required.

Ionic liquids (ILs) are organic molten salts composing of organic cations and inorganic or organic anions. Owing to their distinctive physicochemical properties of high chemical and thermal stability, negligible volatility, ability to dissolve organic/ inorganic solutes and gases, designability, low melting temperature, and low toxicity, ILs have been widely used as solvents, catalysis, monomer, additive, plasticizer, porogenic agent and so on. ${ }^{6,7}$ ILs, employed as a novel and environmentally benign solvents, instead of classical organic ones, have attracted much attentions in the fields of chemistry and industry, such as organic synthesis, polymer preparation, and composite membrane preparation and so on. ${ }^{8-10}$ So far, the traditional free radical polymerization, controlled radical 
polymerization, polycondensation and ionic polymerization have been carried out successfully in ILs. ${ }^{11-13}$

Polycondensation in ILs has been well investigated in the past decades. Polycondensation generally needs harsh conditions (e.g. high temperature, high vacuum, high pressure, etc.) in order to remove condensed small molecules from viscous reaction system and achieve high conversions and molecular weights. It seems to be reasonable to take ILs as reaction media in polycondensation since ILs as "green solvents" have inherently properties.

High molecular weights polyimides, polyamides, polyesters and polysulfones have been synthesized through polycondensation and aromatic nucleophilic substitution polymerization $\left(\mathrm{S}_{\mathrm{N}} \mathrm{AP}\right)$ in conventional ILs by our and other research groups. In 2002, Vygodskii et al. firstly reported that imidazolylcationic ILs, which were used as solvents and catalysts, could been applied for the synthesis of high molecular weights aromatic polyimides and polyamides. ${ }^{14}$ Later, Ohno et al. reported that the polyimides $\left(1.3 \mathrm{dL} \mathrm{g}^{-1}\right)$ could been obtained by addition of zwitterionic type ILs (ZI) in 1-benzyl-3methylimidazolium bis(trifluoromethanesulfonyl)-imide. ${ }^{15}$ Aliphatic polyesters with high molecular weights were synthesized in 1-alkyl-3-methylimidazolium ILs and the correlation between the miscibility of aliphatic polyester and ILs was also investigated. ${ }^{16}$ Poly(ethylene terephthalate) (PET) with high molecular weights was obtained at $190-240{ }^{\circ} \mathrm{C}$ in phenylalkylpyrrolidinium ILs and novel benzyl imidazolium ILs. ${ }^{17}$ High performance polymers polysulfone (PSF), poly(ether sulfone) (PES) and poly(aryl-ether-ketone) (PAEK) with high molecular weights and yields were presented by using IL/ZI as reaction media. ${ }^{18-20}$ Brønsted acidic ionic liquids (BAILs) as both solvents and catalysts and $\mathrm{Tf}_{2} \mathrm{~N}$-anionic ionic liquids as solvents were applied for polycondensation of L-lactic acid and $\varepsilon$-caprolactone. ${ }^{21}$

Herein we report a novel synthetic approach for PPSS with IL/ ZI as reaction media by aromatic nucleophilic substitution polymerization. To the best of our knowledge, it is the first time that PPSS was prepared in ILs. Influences of various polymerization conditions, such as ILs, catalyst, reaction temperature and time was studied.

\section{Experimental section}

\section{Materials}

$N$-Methylimidazole (TCI, $>99 \%$ ) was distilled under reduced pressure. 1,4-Butanesultone (99\%), $n$-butyl bromide (>99\%), potassium hexafluorophosphate $(99 \%)$, and nine hydrated sodium sulfide $\left(\mathrm{Na}_{2} \mathrm{~S} \cdot 9 \mathrm{H}_{2} \mathrm{O}\right)(99 \%)$, benzyl bromide $(>98 \%)$, isopropyl bromide (>99\%) were purchased from Aladdin and utilized as received. $\mathrm{N}$-(2-Hydroxyethyl)-2-pyrrolidone (Energy Chemical, 98\%), phosphorus tribromide (Energy Chemical, 98\%), $N$-isopropvlimdazole (Accela, $>97 \%$ ) were used without further purification. All alkali metal salts and ILs were dried under vacuum before used to eliminate the trace amount of water. 4,4-Difluorodiphenylsulfone (J\&K, 99\%), sodium hydroxide $(\mathrm{NaOH})(\mathrm{AR}$, Tianjing 3rd chemical agent plant) and other solvents were used as received.

\section{Characterization}

The molecular weights analysis was performed using a gel permeation chromatograph (GPC) conducted on a system comprised of a Waters 515 HPLC pump, and a Waters 2414 RI detector equipped with two Agilent columns (PLgel $20 \mu \mathrm{m}$ MIXED-A and PLgel $10 \mu \mathrm{m}$ MIXED-B, PLgel $10 \mu \mathrm{m}$ MIXED-B). DMF with $0.01 \mathrm{M} \mathrm{LiBr}$ was used as the eluent at a flow rate of $1.0 \mathrm{~mL} \mathrm{~min}{ }^{-1}$ at $40{ }^{\circ} \mathrm{C}$, and polystyrene standards were used for the calibration.

IR spectroscopic measurements were conducted on a NEXUS 670 SX FT-IR instrument at a resolution of $1 \mathrm{~cm}^{-1}$. The PPSS powder was dispersed on $\mathrm{KBr}$ disk and measured with the transmission FT-IR spectrum.

${ }^{1} \mathrm{H}$ NMR spectra were recorded at $c a .20{ }^{\circ} \mathrm{C}$ on a Bruker Avance DRX-500 NMR spectrometer in DMSO- ${ }^{6}$ solutions.

XPS analysis was performed on a Perkin-Elmer ESCSLAB 250 Xi spectrometer employing an AlK $\alpha(1361 \mathrm{eV})$ achromatic X-ray source operated at an energy resolution $\leq 0.5 \mathrm{eV}$, space resolution a sensitivity of the $3 \mathrm{~d}_{5 / 2}$ photopeak intensity of silver at 2.5 Mcps. The surface area analyzed was about $3 \mathrm{~mm}^{2}$. The spectrometer was calibrated to the $1 \mathrm{~s}$ photopeak of carbon at $284.4 \mathrm{eV}$.

Powder X-ray diffraction (XRD) patterns were recorded on a PANalytical B.V. XPERT-PROMPD diffractometer using $\mathrm{Cu}$ as anode Material.

Thermogravimetric Analysis (TGA) was carried out on a METTLER STRAE SW 9.30 thermogravimetric analyzer at a heating rate of $10{ }^{\circ} \mathrm{C} \mathrm{min}^{-1}$ in flowing air or nitrogen. Thin film or powder samples of 3-6 $\mathrm{mg}$ were placed in a platinum pan connected to an electric microbalance, and weight loss of the samples was measured as a function of temperature.

Phase transition (mainly glass transitions and melting points) temperatures were recorded from the second heat of the differential scanning calorimetry (DSC) traces on a METTLER TOLEDO instrument with liquid dinitrogen cryostatic cooling (5-8 $\mathrm{mg}$ samples, $10^{\circ} \mathrm{C} \mathrm{min}^{-1}$ heating and cooling rates under a nitrogen atmosphere).

\section{Preparation of ionic liquid}

All ILs and zwitterionic type IL (ZI) used in this work were synthesized according to procedures from literature and the structures of the ILs were confirmed by ${ }^{1} \mathrm{H}$ NMR. ${ }^{16}$

\section{Synthesis of poly(phenylene sulfide sulfone) in mixed ionic liquids}

A series of PPSSs were prepared by $\mathrm{S}_{\mathrm{N}} \mathrm{AP}$ of DFDPS and $\mathrm{Na}_{2} \mathrm{~S}$ in mixed ILs at elevated reaction temperature and atmospheric pressure. Polymerizations were conducted in a $100 \mathrm{~mL}$ threenecked round flask equipped with mechanical stirrer, nitrogen inlet, Dean-Stark trap and reflex condenser. A typical preparation of PPSS was described below. The flask was added $0.36 \mathrm{~g}(1.4 \mathrm{mmol})$ of DFDPS, $0.34 \mathrm{~g}(1.4 \mathrm{mmol})$ of nine hydrated sodium sulfide $\left(\mathrm{Na}_{2} \mathrm{~S} \cdot 9 \mathrm{H}_{2} \mathrm{O}\right), 0.006 \mathrm{~g}(0.14 \mathrm{mmol})$ of sodium hydroxide (NaOH), $0.90 \mathrm{~g}$ of IL and $0.45 \mathrm{~g}$ of ZI. The flask was closed, purged by vacuum/nitrogen cycles using a Schlenk line. 
The mixture was heated to liquid state and stirred vigorously. After the solution was heated up to $140{ }^{\circ} \mathrm{C}, 0.16 \mathrm{~g}(1.5 \mathrm{mmol})$ of ground sodium carbonate $\left(\mathrm{Na}_{2} \mathrm{CO}_{3}\right)$ was added. Then $5-8 \mathrm{~mL}$ of toluene was added and the reaction mixture was refluxed under a Dean-Stark system at $145-155^{\circ} \mathrm{C}$ for $0.5 \mathrm{~h}$. Inleting nitrogen to the flask removed toluene, and the reaction mixture was heated to $200{ }^{\circ} \mathrm{C}$ for $4 \mathrm{~h}$. The obtained brown slurry was cooled to room temperature and mixed with a propanone-water mixture $(1: 1$ $\mathrm{w} / \mathrm{w}, 50 \mathrm{~cm}^{3}$ ), vigorously stirred. An insoluble material was washed with a propanone-water mixture $(1: 1 \mathrm{w} / \mathrm{w}, 2 \times$ $\left.250 \mathrm{~cm}^{3}\right)$ and water $\left(2 \times 250 \mathrm{~cm}^{3}\right)$, then collected by simple filtration. After drying in vacuum at $60^{\circ} \mathrm{C}$ for $24 \mathrm{~h}$, a gray solid product was received. The ILs fraction could be recovered by distillation of volatile solvents from the propanone-water extracts.

\section{Results and discussion}

In our work, PPSSs were synthesized by the reaction of DFDPS and $\mathrm{Na}_{2} \mathrm{~S}$ via $\mathrm{S}_{\mathrm{N}} \mathrm{AP}$ mechanism in the present of $\mathrm{NaOH}$ and $\mathrm{Na}_{2} \mathrm{CO}_{3}$ in IL/ZI. ZI, which is composed of cation and anion, has similar characteristics to general ILs except for high melting point. ZI used in this work was 1-methylimidazolium-3butylsulfonate zwitterion (MImBS) (Scheme 1). Toluene, $\mathrm{Na}_{2} \mathrm{CO}_{3}$ and $\mathrm{NaOH}$ were used as azeotroping solvent, catalyst and additive, respectively.

\section{The identification of PPSS}

In order to confirm PPSS was truly synthesized in IL/ZI system, the PPSS were identified by FT-IR, ${ }^{1} \mathrm{H}$ NMR and XPS. The representative infrared spectra are shown in Fig. $S 1, \dagger$ and the assignments of these absorption peaks are detailed in Table 1. As shown in Fig. S1, $\uparrow$ the characteristic peaks at 1574, 1474 and $1392 \mathrm{~cm}^{-1}$ corresponded to stretch of ring $\mathrm{C}-\mathrm{C}$ (phenyl). The
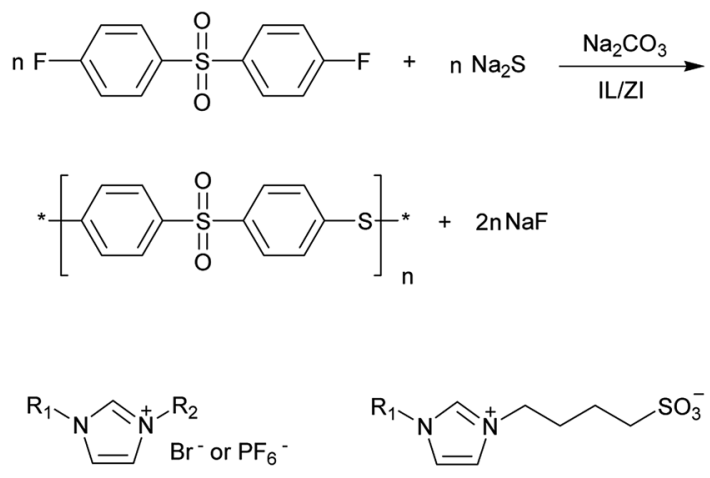

IL

ZI

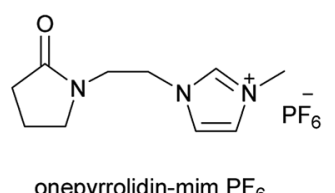

Scheme 1 Synthetic route for PPSS in IL/ZI and structures of imidazolium-based IL and ZI (MImBS).
Table 1 Infrared absorption peaks and assignments of DFDPS and PPSS

\begin{tabular}{|c|c|c|}
\hline \multirow[b]{2}{*}{ Assignment } & \multicolumn{2}{|c|}{ Wavenumber $\left(\mathrm{cm}^{-1}\right)$} \\
\hline & DFDPS & PPSS \\
\hline \multirow{4}{*}{$\begin{array}{l}\mathrm{C}-\mathrm{H} \text { stretch (phenyl) } \\
\text { Ring C-C stretch (phenyl) }\end{array}$} & 3104 & 3082 \\
\hline & 1589 & 1574 \\
\hline & 1493 & 1474 \\
\hline & 1408 & 1392 \\
\hline \multirow{2}{*}{$\begin{array}{l}\text { C-H out-of-plane bend } \\
\text { (phenyl)-para disubstituted } \\
\text { Phenyl-sulfide bond }\end{array}$} & 835 & 817 \\
\hline & - & 1074 \\
\hline Sulfonyl & 1327 & 1321 \\
\hline sym. & 1156 & 1156 \\
\hline
\end{tabular}

absorption peaks at 3082, 817, 1074, 1321 and $1156 \mathrm{~cm}^{-1}$ ascribed to stretch of $\mathrm{C}-\mathrm{H}$ (phenyl), out-of-plane bend of $\mathrm{C}-\mathrm{H}$ (phenyl) at para disubstituted, C-S (phenyl), asymmetric and symmetric stretch of sulfonyl group, respectively. The band at $3414 \mathrm{~cm}^{-1}$, characteristics of water, attributed to moisture absorbed by PPSS. $^{3}$ Compared with that of the monomer DFDPS, red shift of nearly all corresponding characteristic absorption peaks was observed, attributing to the formation of long conjugate $\pi$ bonds. Moreover, the novel absorption peak at $1074 \mathrm{~cm}^{-1}$, belonging to phenyl-sulfide bond, indicated the formation of PPSS.

Fig. S2 $\uparrow$ shows the ${ }^{1} \mathrm{H}$ NMR spectrum and its assignments of PPSS. The two main resonances at $c a$. $7.5 \mathrm{ppm}$ (the hydrogen atoms of phenyl next to sulfide) and $7.9 \mathrm{ppm}$ (the hydrogen atoms of phenyl close to sulfone) implied the symmetric disubstitution of phenyl ring. The integration of peak at $c a$. $7.9 \mathrm{ppm}$ is more than that at $c a$. $7.5 \mathrm{ppm}$, which implied the sulfone moiety is more than that of sulfur in PPSS.

XPS was used to analyze the element composition of PPSS. As shown in Fig. S3, $\dagger$ the sulfur peak at $168.0 \mathrm{eV}$ corresponded to the sulfone moiety in the polymer backbone, the other sulfur peak at $163.9 \mathrm{eV}$ ascribed to the sulfide moiety. ${ }^{1}$ The shoulder of sulfone moiety is higher than the sulfur peak, which implied the sulfone moiety is more than that of sulfur, and the end groups mainly $-\mathrm{F}$ in PPSS. This phenomenon is consistent with that in the ${ }^{1} \mathrm{H}$ NMR spectrum (Fig. S2 $\dagger$ ).

Accordingly, from above results, we can conclude that sulfide and sulfone of phenyl ring in PPSS was symmetric disubstituted and the end groups mainly $-\mathrm{F}$.

In addition, the structure of PPSS can be further explored by XRD. X-ray pattern of PPSS is shown in Fig. S4. $\dagger$ The broad peak at the low scan angle of $19^{\circ}$ shown in Fig. $\mathrm{S} 4 \dagger$ could be ascribe to the amorphous polymer chains of PPSS.

\section{Effect of polymerization conditions}

NMP was most commonly used solvent in traditional preparation process of PPSS. When NMP was used as solvent, 5-8 min was needed to remove toluene by purging nitrogen, and there were some liquid droplets on the inner wall of Dean-Stark trap after purging nitrogen for 5 min. Besides, NMP was reduced 
because of its high volatility. Oppositely, in this study, little liquid droplets on the inner wall was observed by using ILs as solvent, and the time of removing toluene was shortened to 12 min. Simultaneously, the ILs remained unchanged owning to its negligible volatility. Therefore, removing toluene by purging nitrogen became much easier when ILs were used as solvent and the time was shortened significantly. The possible reason is that NMP is mutual solubility with toluene, but ILs are almost not (Table S1 and Fig. S5 $\dagger$ ).

1. Polymerization media. It was found from Table 2 that PPSS with high molecular weights and good yield was obtained in traditional ILs with addition of ZI (entry 1). The ILs used here were i-pmim $\mathrm{PF}_{6}$ and i-pmim $\mathrm{Br}$. Due to the poor solubility of $\mathrm{Na}_{2} \mathrm{~S}$ in pure i-pmim $\mathrm{PF}_{6}$, we introduced $\mathrm{ZI}$ into this system to improve the solubility of $\mathrm{Na}_{2} \mathrm{~S}$ during the synthesis of PPSS. Consequently, good solubility of $\mathrm{Na}_{2} \mathrm{~S}$ was gained when the mass ratio of IL to ZI was $2: 1$, thus no phase separation was observed in the mixture. However, with addition of overmuch ZI, melting temperature and viscosity of IL/ZI system would raise greatly, which were not desired to the synthesis of PPSS. Compared PPSS synthesized in i-pmim $\mathrm{PF}_{6} / \mathrm{MImBS}$ (Table 2, entry 1) with that prepared in i-pmim Br/MImBS (Table 2, entry 2 ), we can clearly know that i-pmim $\mathrm{PF}_{6}$ worked better than ipmim Br. As indicated in entries 3 and 4, when PPSSs were synthesized in i-pmim $\mathrm{PF}_{6} / \mathrm{i}$-pmim $\mathrm{Br}$, yields were all higher than $90 \%$, but $M_{\mathrm{w}}$ were equal or lower than $10^{4}$. When PPSS was synthesized in pure i-pmim $\mathrm{PF}_{6}$, either yield $(1.1 \%)$ or $M_{\mathrm{w}}(1 \times$ $10^{4}$ ) were all low (Table 2, entry 5). Yield was increased to $83.3 \%$ and $M_{\mathrm{w}}$ was $1 \times 10^{4}$ yet as i-pmim Br was used as solvent (Table 2 , entry 6). And the highest molecular weight and good yield were achieved by synthesis of PPSS in i-pmim $\mathrm{PF}_{6} / \mathrm{MImBS}$ (Table 2, entry 1). In addition, pyrrolidine and 1,4-diazabicyclo[2.2.2] octane based ILs were also tested as solvent for the preparation of PPSS, but the molecular weights of PPSS were extremely low.

Above results inferred us that imidazolium-based ILs showed some advantages during the synthesis of PPSS and ZI MImBS may play crucial dual roles of dissolvent and catalyst, leading to the high molecular weight PPSS.

To study the effect of ILs structure on the synthesis of PPSS, except for the ILs, other polymerization variables were kept constant in the whole study (Table 3). ILs, having various anions and different alkyl chain, symmetrical and asymmetrical
Table 3 Influence of ILs on the synthesis of PPSS

\begin{tabular}{llllll}
\hline Entry $^{a}$ & IL & $M_{\mathrm{n}}{ }^{b}\left(10^{4}\right)$ & $M_{\mathrm{w}}{ }^{b}\left(10^{4}\right)$ & PDI $^{b}$ & Yield (\%) \\
\hline 1 & i-pmim $\mathrm{PF}_{6}$ & 1.6 & 2.5 & 1.55 & $>99$ \\
2 & d-ipmim $\mathrm{PF}_{6}$ & 1.0 & 1.3 & 1.27 & 30.1 \\
3 & bmim PF $_{6}$ & 0.9 & 1.1 & 1.25 & 54.3 \\
4 & Onepyrrolidin- & 0.7 & 0.9 & 1.27 & 54.4 \\
& mim PF $_{6}$ & & & & \\
5 & Benzyl-mim PF $_{6}$ & 0.5 & 0.6 & 1.14 & 35.4 \\
6 & i-pmim Br & 0.8 & 1.1 & 1.27 & 91.9
\end{tabular}

${ }^{a}$ General polymerization conditions: equimolar of $\mathrm{Na}_{2} \mathrm{~S} \cdot 9 \mathrm{H}_{2} \mathrm{O}$ and DFDPS, slightly excess of $\mathrm{Na}_{2} \mathrm{CO}_{3}, 0.1$ mole $\mathrm{NaOH}, 25.9$ wt\% monomer concentration, IL : ZI $=2: 1$ by weight, dehydrate at 145$155{ }^{\circ} \mathrm{C}$ for $0.5 \mathrm{~h}$, and then polymerized at $200{ }^{\circ} \mathrm{C}$ for another $4 \mathrm{~h}$. Polymers were washed by propanone-water mixture $(1: 1 \mathrm{w} / \mathrm{w})$ and water, and then collected by simple filtration. ${ }^{b}$ Number-average molecular weight $\left(M_{\mathrm{n}}\right)$, weight-average molecular weight $\left(M_{\mathrm{w}}\right)$ and polydispersity index (PDI) were measured by GPC calibrated with polystyrene standards.

imidazolium cations, were synthesized and studied (Scheme 1). As for the 1-isopropyl-3-methyl-imidazoliumcation, $\mathrm{PF}_{6}{ }^{-}$based ILs showed greater advantages over $\mathrm{Br}^{-}$based ILs according to the molecular weight of PPSS (Table 3, entries 1, 6). It is clear from Table 3, entries 1, 2 that asymmetrical imidazolium-based IL worked better than symmetric one. As the length of alkyl groups in imidazolium was increased from propyl to butyl, molecular weight and yield were all decreased (Table 3, entries $1,3)$. It is speculated that this is related to the interaction of ILs and the monomer. The molecular weights were all lower than $10^{4}$ when PPSS were prepared in benzyl imidazolium ILs or pyrrolidone imidazolium ILs (Table 3, entries 4, 5). The highest molecular weight $\left(2.5 \times 10^{4}\right)$ was gained in $\mathrm{i}$-pmim $\mathrm{PF}_{6} / \mathrm{ZI}$ at yield as high as $>99 \%$ (Table 3 , entry 1). Accordingly, imidazolium-based ILs with short alkyl chain was more desired to synthesis of high molecular weight PPSS. i-pmim $\mathrm{PF}_{6}$ will be used during the following studies.

2. Catalyst. It was reported that PPSSs with high molecular weights were obtained in the presence of alkali metal carboxylate. ${ }^{1}$ Herein we selected several carboxylates and carbonates as catalysts and investigated its influence on the synthesis of PPSS in i-pmim $\mathrm{PF}_{6} / \mathrm{MImBS}$. The molecular weights and yield of

Table 2 Influence of $\mathrm{ZI}$ on the synthesis of PPSS

\begin{tabular}{|c|c|c|c|c|c|}
\hline Entry $^{a}$ & ILs and ZI (weight ratio) & $M_{\mathrm{n}}^{b}\left(10^{4}\right)$ & $M_{\mathrm{w}}^{b}\left(10^{4}\right)$ & $\mathrm{PDI}^{b}$ & Yield (\%) \\
\hline 1 & i-pmim $\mathrm{PF}_{6} / \mathrm{MImBS}=2 / 1$ & 1.6 & 2.5 & 1.55 & $>99$ \\
\hline 2 & i-pmim $\mathrm{Br} / \mathrm{MImBS}=2 / 1$ & 0.8 & 1.1 & 1.27 & 91.9 \\
\hline 3 & $\mathrm{i}$-pmim $\mathrm{PF}_{6} / \mathrm{i}$-pmim $\mathrm{Br}=2 / 1$ & 0.8 & 1.0 & 1.31 & 91.3 \\
\hline 4 & $\mathrm{i}$-pmim $\mathrm{PF}_{6} / \mathrm{i}$-pmim $\mathrm{Br}=1 / 2$ & 0.7 & 0.9 & 1.26 & 91.2 \\
\hline 5 & $\mathrm{i}-\mathrm{pmim} \mathrm{PF}_{6}$ & 0.7 & 1.0 & 1.51 & 1.1 \\
\hline 6 & i-pmim Br & 0.8 & 1.0 & 1.28 & 83.3 \\
\hline
\end{tabular}

${ }^{a}$ General polymerization conditions: equimolar of $\mathrm{Na}_{2} \mathrm{~S} \cdot 9 \mathrm{H}_{2} \mathrm{O}$ and DFDPS, slightly excess of $\mathrm{Na}_{2} \mathrm{CO}_{3}, 0.1 \mathrm{~mole} \mathrm{NaOH}, 25.9$ wt $\%$ monomer concentration, dehydrate at $145-155{ }^{\circ} \mathrm{C}$ for $0.5 \mathrm{~h}$, and then polymerized at $200{ }^{\circ} \mathrm{C}$ for another $4 \mathrm{~h}$. Polymers were washed by propanone-water mixture $(1: 1 \mathrm{w} / \mathrm{w})$ and water, and then collected by simple filtration. ${ }^{b}$ Number-average molecular weight $\left(M_{\mathrm{n}}\right)$, weight-average molecular weight $\left(M_{\mathrm{w}}\right)$ and polydispersity index (PDI) were measured by GPC calibrated with polystyrene standards. 
Table 4 Influence of catalyst on the synthesis of PPSS

\begin{tabular}{llllll}
\hline Entry $^{a}$ & Catalyst & $M_{\mathrm{n}}{ }^{b}\left(10^{4}\right)$ & $M_{\mathrm{w}}{ }^{b}\left(10^{4}\right)$ & $\mathrm{PDI}^{b}$ & Yield (\%) \\
\hline 1 & $\mathrm{Na}_{2} \mathrm{CO}_{3}$ & 1.6 & 2.5 & 1.55 & $>99$ \\
2 & $\mathrm{~K}_{2} \mathrm{CO}_{3}$ & 0.8 & 1.1 & 1.35 & 68.5 \\
3 & $\mathrm{CH}_{3} \mathrm{COONa}$ & 0.9 & 1.1 & 1.29 & 61.4 \\
4 & $\mathrm{CH}_{3} \mathrm{COOK}$ & 1.2 & 1.6 & 1.37 & 78.7 \\
5 & $\mathrm{C}_{6} \mathrm{H}_{5} \mathrm{COOK}$ & 1.2 & 1.6 & 1.38 & 93.2
\end{tabular}

${ }^{a}$ General polymerisation conditions: equimolar of $\mathrm{Na}_{2} \mathrm{~S} \cdot 9 \mathrm{H}_{2} \mathrm{O}$ and DFDPS, slightly excess of catalyst, 0.1 mole $\mathrm{NaOH}, 25.9 \mathrm{wt} \%$ monomer concentration, IL : ZI $=2: 1$ by weight, dehydrate at $145-155{ }^{\circ} \mathrm{C}$ for $0.5 \mathrm{~h}$, and then polymerized at $200{ }^{\circ} \mathrm{C}$ for another $4 \mathrm{~h}$. Polymers were washed by propanone-water mixture $(1: 1 \mathrm{w} / \mathrm{w})$ and water, and then collected by simple filtration. ${ }^{b}$ Number-average molecular weight $\left(M_{\mathrm{n}}\right)$, weight-average molecular weight $\left(M_{\mathrm{w}}\right)$ and polydispersity index (PDI) were measured by GPC calibrated with polystyrene standards.

Table 5 Influence of $\mathrm{NaOH}$ on the synthesis of PPSS

\begin{tabular}{llllll}
\hline Entry $^{a}$ & $\mathrm{NaOH} / \mathrm{Na}_{2} \mathrm{CO}_{3} / \mathrm{Na}_{2} \mathrm{~S}$ & $M_{\mathrm{n}}{ }^{b}\left(10^{4}\right)$ & $M_{\mathrm{w}}{ }^{b}\left(10^{4}\right)$ & $\mathrm{PDI}^{b}$ & Yield (\%) \\
\hline 1 & $1 / 10 / 10$ & 1.6 & 2.5 & 1.55 & $>99$ \\
2 & $0 / 10 / 10$ & 1.1 & 1.4 & 1.32 & 91.4 \\
3 & $2 / 10 / 10$ & 0.5 & 0.6 & 1.19 & 61.9 \\
4 & $1 / 0 / 10$ & 0.6 & 0.8 & 1.31 & 82.5
\end{tabular}

${ }^{a}$ General polymerization conditions: equimolar of $\mathrm{Na}_{2} \mathrm{~S} \cdot 9 \mathrm{H}_{2} \mathrm{O}$ and DFDPS, slightly excess of $\mathrm{Na}_{2} \mathrm{CO}_{3}, 25.9$ wt\% monomer concentration, IL : ZI $=2: 1$ by weight, dehydrate at $145-155{ }^{\circ} \mathrm{C}$ for $0.5 \mathrm{~h}$, and then polymerized at $200{ }^{\circ} \mathrm{C}$ for another $4 \mathrm{~h}$. Polymers were washed by propanone-water mixture $(1: 1 \mathrm{w} / \mathrm{w})$ and water, and then collected by simple filtration. ${ }^{b}$ Number-average molecular weight $\left(M_{\mathrm{n}}\right)$, weightaverage molecular weight $\left(M_{\mathrm{w}}\right)$ and polydispersity index (PDI) were measured by GPC calibrated with polystyrene standards.

PPSSs obtained using different catalysts are listed in Table 4. It is apparent from Table 4 that $\mathrm{Na}_{2} \mathrm{CO}_{3}$ worked best among all of the carboxylates and carbonates we chose, and both highest molecular weight and yield were obtained. Consequently, $\mathrm{Na}_{2} \mathrm{CO}_{3}$ was selected as catalyst in this study.

3. Additive. We also investigated the effect of $\mathrm{NaOH}$ on the synthesis of PPSS. Table 5 shows that $\mathrm{NaOH}$ play a vital role for the high molecular weights PPSS. The maximum molecular weight was obtained when the molar ratio of $\mathrm{NaOH} / \mathrm{Na}_{2} \mathrm{~S}$ was $1 /$ 10 (Table 5 , entry 1 ). In contrast, when excess $\mathrm{NaOH}$ was added, that is, molar ratio of $\mathrm{NaOH} / \mathrm{Na}_{2} \mathrm{~S}$ was increased to 2/10, PPSS with lower degree of polymerization was gained (Table 5 , entry 3). This inferred that excess $\mathrm{NaOH}$ would interfere with the synthesis of PPSS. However, molecular weight was not high yet while no $\mathrm{NaOH}$ was used during the preparation of PPSS (Table 5 , entry 2). The possible reasons are as follows. Because of the strong basic group and the weak acidic group of $\mathrm{Na}_{2} \mathrm{~S}$, it is unstable and decomposes very easily. When appropriate amount of $\mathrm{NaOH}$ was added, it could regulate acidity and alkalinity of the polymerization system, so that $\mathrm{Na}_{2} \mathrm{~S}$ became more stable and could work as monomer to participate in the synthesis of PPSS. However, excess $\mathrm{NaOH}$ resulted in the degradation of PPSS attributing to the chemical attack of the sulfur-carbon bonds in the polymer chain by excessive $\mathrm{OH}^{-}$at elevated temperature. ${ }^{1}$ From Table 5, entry 4 , one can see that molecular weights decreased to lower than $10^{4}$ as only $\mathrm{NaOH}$ was added but no $\mathrm{Na}_{2} \mathrm{CO}_{3}$ was used.

Above results shown in Tables 4 and 5 implied that both $\mathrm{Na}_{2} \mathrm{CO}_{3}$ contributing to the high molecular weights and $\mathrm{NaOH}$ contributing to the stability of $\mathrm{Na}_{2} \mathrm{~S}$ were indispensable and irreplaceable during the preparation of PPSS.

4. Polymerization temperature. In order to search optimum polymerization conditions, the influence of polymerization temperature on the preparation of PPSS was examined in i-pmim $\mathrm{PF}_{6} / \mathrm{MImBS}$. Except for polymerization temperature varied from 160 to $210{ }^{\circ} \mathrm{C}$, other polymerization variables were kept constants in the whole study including the weight percentage of DFDPS of $25.9 \mathrm{wt} \%$, molar ratio of $\mathrm{Na}_{2}$ $\mathrm{S} \cdot 9 \mathrm{H}_{2} \mathrm{O} / \mathrm{DFDPS}$ of $1 / 1$, molar ratio of $\mathrm{Na}_{2} \mathrm{~S} \cdot 9 \mathrm{H}_{2} \mathrm{O} / \mathrm{NaOH} / \mathrm{Na}_{2} \mathrm{CO}_{3}$ of $1 / 0.1 / 1$, and polymerization time of $4 \mathrm{~h}$ at atmospheric pressure. $M_{\mathrm{n}}$ and $M_{\mathrm{w}}$ of PPSS are plotted in Fig. 2 as function of polymerization temperature. As shown in Fig. 2, with the increase of polymerization temperature from $160{ }^{\circ} \mathrm{C}$ to $200{ }^{\circ} \mathrm{C}$, the molecular weights increase gradually and the color of PPSS became dark. The highest molecular weights was obtained at $200{ }^{\circ} \mathrm{C}$. However, when we continued to raise the polymerization temperature, the molecular weights decrease. This may attribute to the degradation of PPSS under basic environment at high temperature.

5. Polymerization time. The influence of polymerization time on the preparation of PPSS was also examined by varying the polymerization time from $0.5 \mathrm{~h}$ to $6 \mathrm{~h}$ in i-pmim $\mathrm{PF}_{6} /$ MImBS. The temporal evolution of molecular weights is shown in Fig. 3. As indicated in Fig. 3, with increasing polymerization time from $0.5 \mathrm{~h}$ to $4 \mathrm{~h}$, the molecular weights of PPSS became larger and larger. And the highest molecular weight was acquired as the polymerization time was $4 \mathrm{~h}$. Contrastly, when we continued to prolong the polymerization time, the molecular weights of PPSS no longer increased but decreased. It is speculated that overlong polymerization time may result in the decomposition of PPSS and side reactions so that the molecular weights decreased continuously from $4 \mathrm{~h}$ to $6 \mathrm{~h}$.

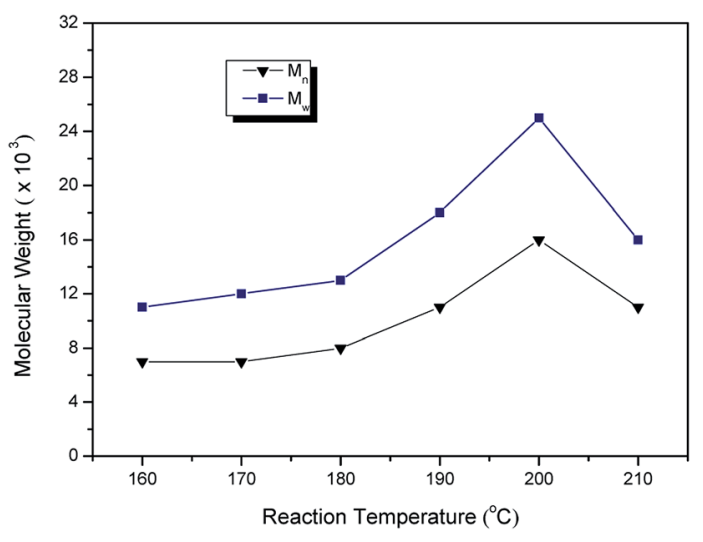

Fig. 2 Variation of $M_{n}$ and $M_{w}$ of PPSS versus polymerization temperature in i-pmim $\mathrm{PF}_{6} / \mathrm{MImBS}$ (25.9 wt\% of DFDPS, molar ratio of $\mathrm{Na}_{2} \mathrm{~S} \cdot 9 \mathrm{H}_{2} \mathrm{O} /$ DFDPS of $1 / 1$, molar ratio of $\mathrm{Na}_{2} \mathrm{~S} \cdot 9 \mathrm{H}_{2} \mathrm{O} / \mathrm{NaOH} / \mathrm{Na}_{2} \mathrm{CO}_{3}$ of $1 / 0.1 / 1$, reaction time of $4 \mathrm{~h}$ at atmospheric pressure). 


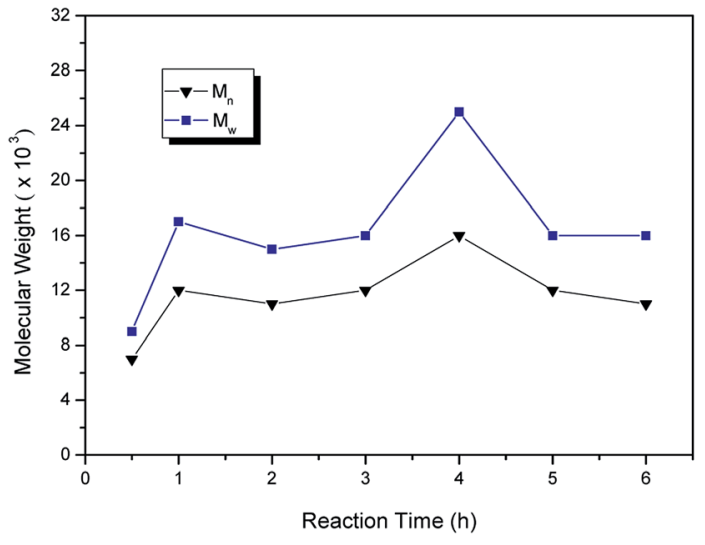

Fig. 3 The temporal evolution of $M_{n}$ and $M_{w}$ of PPSS in i-pmim $\mathrm{PF}_{6} /$ MimBS (25.9\% weight percentage of DFDPS, molar ratio of $\mathrm{Na}_{2}-$ $\mathrm{S} \cdot 9 \mathrm{H}_{2} \mathrm{O} /$ DFDPS of $1 / 1$, molar ratio of $\mathrm{Na}_{2} \mathrm{~S} \cdot 9 \mathrm{H}_{2} \mathrm{O} / \mathrm{NaOH} / \mathrm{Na}_{2} \mathrm{CO}_{3}$ of $1 /$ $0.1 / 1$, polymerization temperature of $200{ }^{\circ} \mathrm{C}$ at atmospheric pressure).

From above study, the optimum polymerization condition for synthesis of PPSS was achieved in i-pmim $\mathrm{PF}_{6} / \mathrm{MImBS}$ (25.9 wt $\%$ monomer concentration, ratio of i-pmim $\mathrm{PF}_{6} / \mathrm{MImBS}$ (weight), $\mathrm{Na}_{2} \mathrm{~S} \cdot 9 \mathrm{H}_{2} \mathrm{O} /$ DFDPS (molar) and $\mathrm{Na}_{2} \mathrm{~S} \cdot 9 \mathrm{H}_{2} \mathrm{O} / \mathrm{NaOH} /$ $\mathrm{Na}_{2} \mathrm{CO}_{3}$ (molar) was $2: 1,1 / 1$, and $1 / 0.1 / 1$, respectively, polymerized at $200{ }^{\circ} \mathrm{C}$ and atmospheric pressure for $4 \mathrm{~h}$ ).

\section{Thermal properties of PPSS}

TGA and DSC have proved to be suitable methods to investigate the thermal property of polymeric systems. The threshold decomposition temperature in TGA gives an indication of the highest processing temperature that can be used. Fig. 4 depicts TGA curves of PPSS in nitrogen and air, respectively. PPSS showed two-step weight loss progress in air: between 350 and $520{ }^{\circ} \mathrm{C}$, and above $520{ }^{\circ} \mathrm{C}$. The process at $350-520{ }^{\circ} \mathrm{C}$ is attributed to the degradation of sulfone moiety in the polymer backbone. The second degradation above $520{ }^{\circ} \mathrm{C}$ is ascribed to the decomposition of sulfide moiety. The temperature of $5 \%$ weight loss of PPSS was over $400{ }^{\circ} \mathrm{C}$ in nitrogen, and the char yield values at $700{ }^{\circ} \mathrm{C}$ was $8.1 \%$ in air and $48.4 \%$ in nitrogen, respectively. The glass transition temperature $\left(T_{\mathrm{g}}\right)$ of PPSS were measured by DSC and showed up to $206{ }^{\circ} \mathrm{C}$, as illustrated in Fig. $5 .^{22,23}$

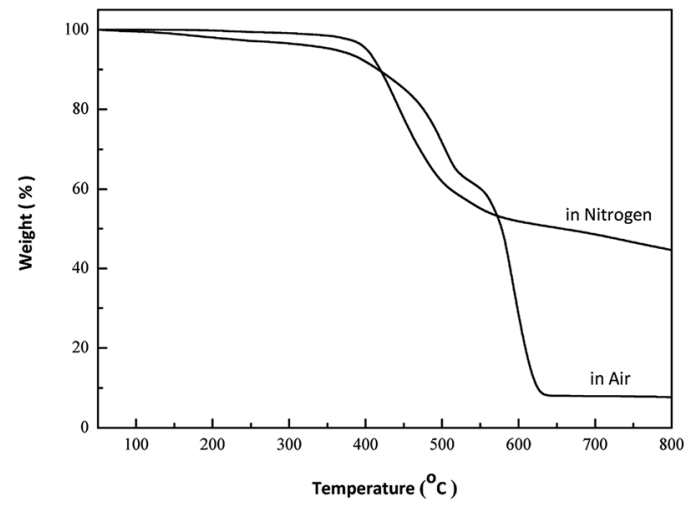

Fig. 4 TGA of PPSS at the heating rate of $10^{\circ} \mathrm{C} \mathrm{min}^{-1}$.

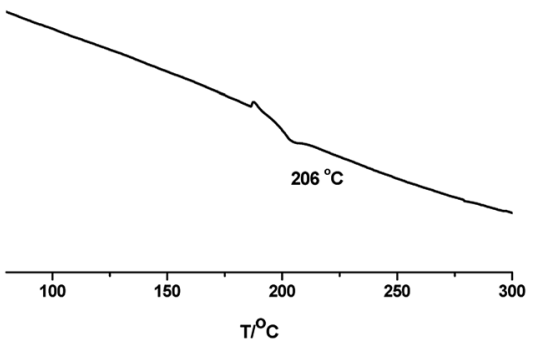

Fig. 5 DSC trace of PPSS

\section{Recycle and reuse of ionic liquid}

The main advantage of ILs over conventional organic solvents as solvent is facile to recycle and reuse after polymerization, which is absolutely very intriguing from the viewpoint of environmental conservation and economic benefits. In our study, the solid product was precipitated into propanone under mechanical stirrer, and the PPSS and IL i-pmim $\mathrm{PF}_{6}$ were separated by filtration. After that, the residual i-pmim $\mathrm{PF}_{6}$ in the filtrate and propanone were recycled by vacuum evaporation. And white solid was obtained ultimately and no oligomer residue was observed in them. FTIR spectra of i-pmim $\mathrm{PF}_{6}$ before and after use in polymerization were performed (Fig. S6†). The characteristic peak at $840 \mathrm{~cm}^{-1}$ was assigned to the $\mathrm{P}-\mathrm{F}$ bond of $\mathrm{PF}_{6}{ }^{-}$. The absorption peaks at 3093 and $1322 \mathrm{~cm}^{-1}$ ascribed to stretch of $\mathrm{C}-\mathrm{H}$ (phenyl) and asymmetric stretch of sulfonyl group of DFDPS. The absorption peak at $1062 \mathrm{~cm}^{-1}$ belonged to sulfide. These indicated that IL i-pmim $\mathrm{PF}_{6}$ underwent virtually no decomposition throughout the polymerization. The recycled i-pmim $\mathrm{PF}_{6}$ was also analyzed by ${ }^{1} \mathrm{H}$ NMR (Fig. S7 $\dagger$ ). Fig. S6† indicated that no obvious change of the chemical shifts of i-pmim $\mathrm{PF}_{6}$ and little remaining monomer was observed after synthesis of PPSS. To confirm the validity of recycled ILs, $S_{N} R P$ between DFDPS and $\mathrm{Na}_{2} \mathrm{~S}$ was performed in recycled ILs. Although the molecular weight of PPSS prepared in recycled IL was slightly lower $\left(M_{\mathrm{w}}=15000\right)$, it still illustrated that the recycled ILs could be applicable in new polymerization cycle, even after more several cycles.

\section{Conclusions}

In this work, a series of PPSSs were prepared successfully via $\mathrm{S}_{\mathrm{N}} \mathrm{AP}$ based on $\mathrm{Na}_{2} \mathrm{~S}$ and DFDPS in IL/ZI at atmospheric pressure, which was different from other studies conducted at high pressure. The highest molecular weight $\left(2.5 \times 10^{4}\right)$ and yield (>99\%) PPSS were synthesized in i-pmim $\mathrm{PF}_{6}$ (IL)/MImBS (ZI) in the presence of $\mathrm{Na}_{2} \mathrm{CO}_{3}$ and $\mathrm{NaOH}$ at $200{ }^{\circ} \mathrm{C}$ for $4 \mathrm{~h}$. The structure of PPSS was confirmed by FT-IR, ${ }^{1} \mathrm{H}$ NMR, XPS and XRD.

The influence factors of the polymerization, such as catalyst, additive, polymerization media, polymerization temperature and polymerization time were all investigated. And it showed that optimum polymerization conditions for synthesis of PPSS was relatively mild in i-pmim $\mathrm{PF}_{6}$ and MImBS (weight ratio of IL to ZI was $2: 1$, monomer concentration was $25.9 \mathrm{wt} \%$, the 
polymerization temperature was $200{ }^{\circ} \mathrm{C}$ and the polymerization time was $4 \mathrm{~h}$ ). ZI can significantly improve the solubility of basic inorganic salt $\mathrm{Na}_{2} \mathrm{~S}$, thus PPSS with high molecular weights and good yield was obtained. Appropriate amount of $\mathrm{NaOH}$ contributed to synthesis of PPSS but excess interfered. Using ILS as solvent made remove toluene by purging nitrogen much easier and the time was shortened obviously from 5-8 min to 12 min. For ILs with different coupling of cation and anion, imidazolium-based ILs with short alkyl chain was favorable to synthesis of high molecular weights PPSS. ILs was facile to recycle and reuse after polymerization and it also had excellent recyclability in this polymerization system.

It is possible to improve the degrees of polymerization by further designing of the cation and anion of the ILs, and thus deserves further research.

\section{Acknowledgements}

This work was financially supported by the National Natural Science Foundation of China (No. 21274014), the Fundamental Research Funds for the Central Universities, Program for Changjiang Scholars and Innovative Research Team in University, and Measuring Fund of Large Apparatus of Beijing Normal University.

\section{Notes and references}

1 Y. Liu, A. Bhatnagar, Q. Ji, J. S. Riffle, J. E. McGrath, J. F. Geibel and T. Kashiwagi, Polymer, 2000, 41, 5137-5146.

2 L. Liu, X. Wang, Y. Wang, L. Li, K. Pan, J. Yang and B. Cao, Mater. Lett., 2014, 132, 11-14.

3 J. Yang, H.-D. Wang, S.-X. Xu, G.-X. Li and Y.-J. Huang, J. Polym. Res., 2005, 12, 317-323.

4 R. W. Capbell, US Pat. 4, 016, 145, 1977.

5 R. W. Capbell, US Pat. 4, 125, 525, 1978.
6 C. C. Weber, A. F. Masters and T. Maschmeyer, Green Chem., 2013, 15, 2655-2679.

7 J. Lu, F. Yan and J. Texter, Prog. Polym. Sci., 2009, 34, 431448.

8 D. S. Lakshmi, T. Cundari, E. Furia, A. Tagarelli, G. Fiorani, M. Carraro and A. Figoli, Macromol. Symp., 2015, 357, 159167.

9 Z. Yi, C.-J. Liu, L.-P. Zhu and Y.-Y. Xu, Langmuir, 2015, 31, 7970-7979.

10 E. Coletta, M. F. Toney and C. W. Frank, Polymer, 2014, 55, 6883-6895.

11 C. Zhang, L. Liao and S. Gong, Green Chem., 2007, 9, 303314.

12 J.-S. Wang and K. Matyjaszewski, J. Am. Chem. Soc., 1995, 117, 5614-5615.

13 T. Biedroń, M. Bednarek and P. Kubisa, Macromol. Rapid Commun., 2004, 25, 878-881.

14 Y. S. Vygodskii, E. I. Lozinskaya and A. S. Shaplov, Macromol. Rapid Commun., 2002, 23, 676-680.

15 M. Tamada, T. Hayashi and H. Ohno, Tetrahedron Lett., 2007, 48, 1553-1557.

16 C. Fu and Z. Liu, Polymer, 2008, 49, 461-466.

17 J. Dou and Z. Liu, Green Chem., 2012, 14, 2305-2313.

18 J. Wang and Z. Liu, Green Chem., 2012, 14, 3204-3210.

19 J. Wang and Z. Liu, Chin. Sci. Bull., 2013, 58, 1262-1266.

20 J. Wang, Y. Wu and Z.-p. Liu, Chin. J. Polym. Sci., 2016, 34, 981-990.

21 Q. Peng, K. Mahmood, Y. Wu, L. Wang, Y. Liang, J. Shen and Z. Liu, Green Chem., 2014, 16, 2234-2241.

22 H. Wang, J. Yang, S. Long, X. Wang, Z. Yang and G. Li, Polym. Degrad. Stab., 2004, 83, 229-235.

23 A. P. Gies, S. T. Ellison, J. F. Geibel and D. M. Hercules, Macromolecules, 2011, 44, 5093-5104. 